Chapter 7

\title{
Synthesis, Properties and Physical Applications of IoNanofluids
}

\author{
Carlos Nieto de Castro, Ana P. C. Ribeiro, \\ Salomé I.C. Vieira, João M. P. França, \\ Maria J.V. Lourenço, Fernando V. Santos, \\ Sohel M.S Murshed, Peter Goodrich and \\ Christopher Hardacre
}

Additional information is available at the end of the chapter

http://dx.doi.org/10.5772/52596

\section{Introduction}

Ionic liquids have proved to be one of the most impressive classes of fluids, due to their properties and applications to chemistry and engineering. One of the most recent applications of complex systems of ionic liquids and nanomaterials are IoNanofluids, from heat transfer to catalysis, solar absorbing panels, lubricants or luminescent materials. These novel materials belong to the class of nanofluids proposed in the last years and are a mixture of ionic liquid and nanomaterial, in the form of nanoparticle dispersion, and have already resulted in a number of publications in chemical and physical journals.

There are several reasons to study these new materials/fluids, rather complex in structure. The most important property is their enhanced thermal properties, like thermal conductivity and heat capacity, heat transfer and heat storage. The complex interactions existing between the anion/cation of the ionic liquid and the nanomaterial surface create nano-regions that can enhance reactivity and selectivity of chemical reactions. As the physiochemical properties of ionic liquids themselves can be tailored to the desired application employing an ionic liquid as a base fluid means IoNanofluids can also be designed to meet any specific application or task requirement. They also are non-flammable and non-volatile at ambient conditions and can, therefore, be considered as "green" fluids. 
The possible scientific, technical and economic success of IoNanofluids open new markets, as new products for engineering fluids, heat insulators, catalysts, etc., can be envisaged. In addition, the replacement of environmentally aggressive chemicals, foams, solid composites are in daily order, imposed by regulations or social responsibility. These new challenges open new jobs for chemists, material scientists and engineers.

The precursors of the IoNanofluids are nanofluids. Their impact in the scientific/ technical literature is very big. A total of 1575 nanofluids related publications, which include journal and conference articles, patent, news, letter and other, have appeared over the past 11 years. ${ }^{1}$ In Figure 1 it can be seen an exponential growthof the total number of these items published per year since 2002. It is also believed that there are more than 300 research groups and companies worldwide involved in nanofluids research, a hot topic in an interdisciplinary field. Several spin-off companies have originated from nanofluids research and the number continues to increase.

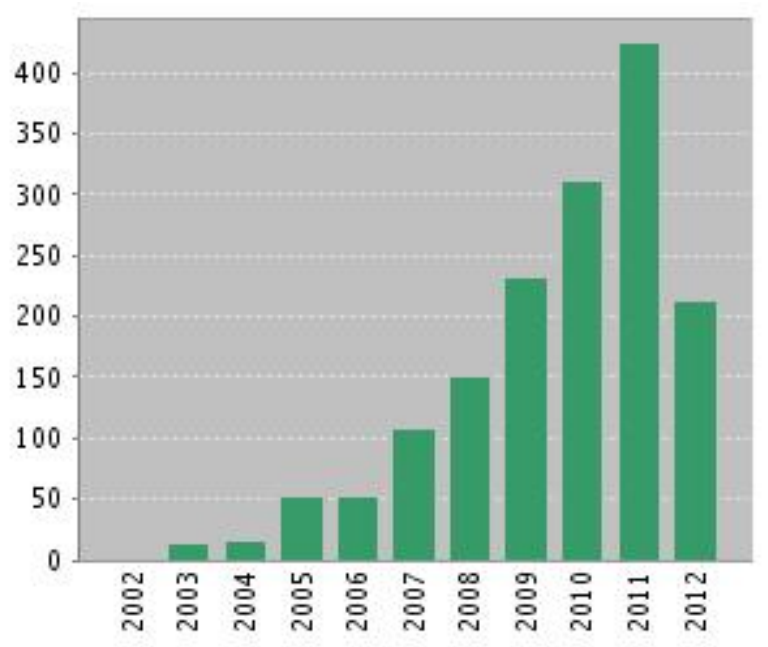

Figure 1. Web of Knowledge record of nanofluids related publications

The current review, which focuses the syntheses of ionic liquids, the preparation of IoNanofluids, their properties, experimental measurements, processes requirements and economic impact, pretends to contribute to clarify the overall question, always present in the appearance of a new field, which crosses several minds: Will IoNanofluids be useful to our society?

Comparison between the IoNanofluids properties and those of the base ionic liquids will be the key for understanding the role of the interface between the ionic liquid and the nanomaterial in the determination of physical properties. The unexpected behavior observed in 
some IoNanofluids and the difference observed regarding the base fluid is, in our view, the most important aspect in this review.

\section{Ionic Liquids}

Ionic liquids (ILs) are materials composed entirely of ions, which have melting points below $100{ }^{\circ} \mathrm{C}[1]$. Such liquids are an elaborate network of ions which are governed by electrostatic charges and hydrogen bonding [2]. More recently room temperature ionic liquids (RTILs) have moved to the forefront of IL research due to their melting temperatures being below $30^{\circ} \mathrm{C}$. Generally the asymmetric form of the ions (usually the cation) reduces the Coulombic interactions which results in a lowering of the melting points, see figure 2 . These liquids exhibit favourable properties for solvent use due to the formation of air and moisture stable, lowvolatile liquids, low flammability [3] under ambient conditions high ionic conductivity which also maintains their thermal and electrical stability over a large temperature range $[4,5]$. With judicious tailoring of the cation-anion structure a range of ILs can be synthesised with various pre-chosen physiochemical properties. This has resulted in them being applied in a multitude of techniques including catalysis [6], elemental analysis [7], synthesis [8], solar absorbing panels [9], lubricants [10], luminescent materials [11] and supercritical fluids $[12,13]$. Ionic liquids also provide very different solvent-solute interactions which can give rise to distinct chemistries compared with molecular solvent systems [14]. In addition to this, the use of ILs acting as both the solvent system and reactant/catalyst in a reaction process [15] makes them a "hot topic" for researchers. They have also been shown to immobilize and stabilize catalytic complexes or even act as modifiers that accelerate the reaction [16]. These IL-catalyst systems can be recycled potentially reducing chemical waste and increasing the lifetime of the catalyst, further adding to the 'green' aspects of ionic liquids [17]. More recent understanding and analysis of catalytic reactions show that even so called benign ILs are now not considered chemically passive and are capable of modifying the catalyst resulting in differing chemistries [18].

Pioneering physical and chemical research in ILs where usually focused on imidazolium based cations with the corresponding tetrafluoroborate $\left(\left[\mathrm{BF}_{4}\right]^{-}\right)$or hexafluorophosphate $\left(\left[\mathrm{PF}_{6}\right]^{-}\right)$anions. These were initially chosen due to their ease of synthesis and purification. However, these ILs have been found to be of lower thermal stability and undergo hydrolysis reactions resulting in the production of $\mathrm{HF}$ and $\mathrm{BF}_{3}$ [19]. Recently, hydrophilic fluorine based anions such as bis(trifluorosulfonyl)imide $\left(\left[\mathrm{NTf}_{2}\right]^{-}\right)$and the tris(perfluoroalkyl)trifluorophosphate ([FAP] $]^{-}$have been developed. The stability of these anions is well established and has found many applications in the fields of catalysis [20]. Other halide free anions include alklysulfate, alkylphosphate and alklycarbonate molecules.

The synthesis of all ionic liquids starts with the 'neutralisation' of a Lewis base, typically alkylimidazoles, trialkylamines including pyrolles and piperidines, trialkylphopshines and pyridines are the most frequently used. For the synthesis of protic ILs, the Lewis base (represented as methylimidazole) can be neutralised directly by the addition of a Brönsted acid, 
see Figure 3, step 1 . However, some of these salts are generally thermally unstable or exist in equilibrium with the free acid and base thus limiting their applications [21].<smiles>[R]n1cc[n+]([R])c1</smiles><smiles>[R][n+]1ccsc1</smiles><smiles>[R]OS(=O)(=O)[O-]</smiles><smiles>[R5][Se]</smiles><smiles>N#C[N-]C#N</smiles>

$\left[\mathrm{N}\left(\mathrm{CN}_{2}\right]^{-}\right.$<smiles>F[B-](F)(F)F</smiles>

$\left[\mathrm{BF}_{4}\right]$<smiles>[R][n+]1ccccc1</smiles><smiles>[R][N+]1([R])CCCC1</smiles><smiles>[R][N+]([R])([R])C</smiles><smiles>[R][P+]([R7])([R7])C</smiles>
$\mathrm{Br}^{-}$<smiles>F[P-](F)(F)(F)(F)F</smiles>

$\left[\mathrm{PF}_{6}\right]^{-}$<smiles>FC(F)(F)C(F)(F)C(F)(F)P(F)(F)(C(F)(F)F)C(F)(F)F</smiles>

[FAP]<smiles>O=S(=O)([N-]S(=O)(=O)C(F)(F)F)C(F)(F)F</smiles>

$\left[\mathrm{NTf}_{2}\right]^{-}$

Figure 2. Common cations and anions used in air and moisture stable RTILs

For many ILs the preparation is strongly associated with the considerations about the required purity of the ILs post synthesis. For example in the synthesis of imidazolium ILs, the most common synthetic strategy involves the synthesis of the corresponding commercially available alkylimidazolium halide $\left(\mathrm{Cl}^{-}\right.$or $\left.\mathrm{Br}^{-}\right)$followed by anion metathesis to the desired $\mathrm{IL}$, see Figure 3, steps 2 and 3. For hydrophobic ILs such as those containing the $\left[\mathrm{NTf}_{2}\right]^{-}$and $\left[\mathrm{PF}_{6}\right]^{-}$anions, this can be achieved by anion exchange of the imidazolium halide with the corresponding $\mathrm{Li}^{+}, \mathrm{Na}^{+}$or $\mathrm{NH}_{4}{ }^{+}$salt. Therein, the IL forms a separate phase which can be further purified by washing with water to remove any remaining halide. The water solubility of the ILs is very dependent on both the anion and cation present, and in general will decrease with increasing organic character (alkyl chain length) of the cation and decrease with increasing fluorinated character in the anion. For hydrophilic ILs such as those containing the, $\left[\mathrm{RSO}_{4}\right]^{-}\left[\mathrm{CF}_{3} \mathrm{SO}_{2}\right]^{-},\left[\mathrm{BF}_{4}\right]^{-}$or $\left[\mathrm{N}(\mathrm{CN})_{2}\right]^{-}$anions the corresponding $\mathrm{Ag}^{+}$salt is used to precipitate out $\mathrm{Ag}$ halide salt which can be removed by filtration.

Impurities in ILs such as water, halides, starting materials and organic solvents not only have a profound effect on their physical properties [22] but have also resulted in significant changes in reaction chemistry [23-27]. Within both these areas significant steps have been made in the creation of cleaner and more economic routes to the preparation of ILs [28,29].

Other so halide free synthetic pathways involve direct alklylation to form the corresponding, alkylsulphate $\left(\left[\mathrm{RSO}_{4}\right]^{-}\right)$, alkylcarbonate $\left(\left[\mathrm{RCO}_{3}\right]^{-}\right)$and trilfate $\left(\left[\mathrm{CF} 3 \mathrm{SO}_{2}\right]^{-}\right)$ILs, see Figure 3, step 4. The alkylsulphate [30] or alkylcarbonate [31] ILs which have found applications in their own right can be further reacted to form the corresponding halide free hydrophilic ILs. 


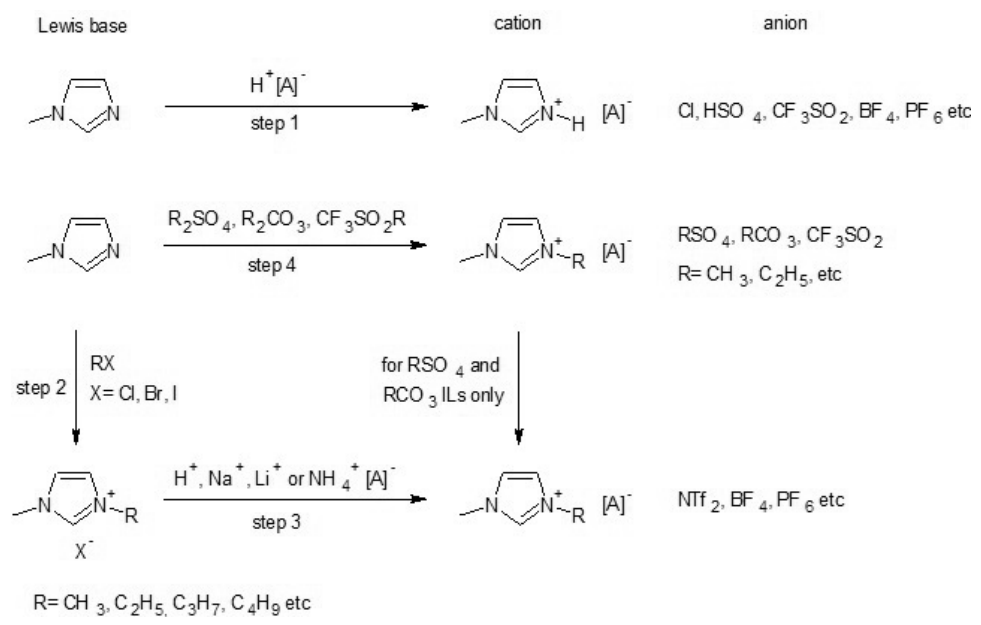

Figure 3. General synthesis of air stable, metal free lonic liquids

\section{IoNanofluids}

IoNanofluids are complex systems of nanofluids with nanomaterials. Before we deal directly with these systems, a brief digression in the field of nanofluids will help to clarify the properties and these especial fluids. The origin of the nanofluids is linked to the current challenges faced by many high-tech industries and thermal management systems for cooling of smaller features of microelectronic and more power output-based devices. The conventional method to increase the cooling rate is to use extended heat transfer surfaces but this approach requires an undesirable increase in the size of the thermal management systems. This fact, added to the thermophysical properties of the traditionally heat transfer fluids (HTFs) used in industry, such as water, ethylene glycol (EG) or engine oil (EO) greatly limit the cooling performance. This situation was partially overcome by the use of materials with high thermal conductivity, such as nanomaterials suspended or dispersed in this type of base fluids. Choi [32] at Argonne National Laboratory of USA coined the concept of "nanofluids" to meet the aforementioned cooling challenges facing many advanced industries and devices. This new class of heat transfer fluids is engineered by dispersing nanometer-sized solid particles, rods or tubes in traditional heat transfer fluids and they were found to exhibit significantly higher thermophysical properties, particularly thermal conductivity and thermal diffusivity than those of base fluids (BFs) [33-38].

From practical application-based studies such as convective and boiling heat transfer characteristics [39-45], nanofluids (NFs) were also found to be even more promising as their convective heat transfer coefficient and critical heat flux were reported to be substantially higher as compared to those of their base fluids. In particular, nanofluids containing high thermal conductive materials such as carbon nanotubes (CNTs) shows anomalously en- 
hanced thermal performance [45-47]. This is justified by the great difference between thethermal conductivity of CNTs (between 2000 and $3000 \mathrm{Wm}^{-1} \mathrm{~K}^{-1}$ ) and that of the base fluid $\left(0.6 \mathrm{Wm}^{-1} \mathrm{~K}^{-1} \text { for water }\right)^{2}$

The concept of "IoNanofluids" was recently proposed by Nieto de Castro and co-workers [48] and it represents a very new class of heat transfer fluids where nanomaterials (particles, tubes and rods) are dispersed in ionic liquids only [49]. Since IoNanofluids are a specific type of nanofluids i.e., ionic liquids-based nanofluids, they are expected to have similar thermal properties than nanofluids, a fact that was proved recently by the authors [50]. The term IoNanofluids is therefore a new term in multidisciplinary fields such as nanoscience, nanotechnology, thermofluidity, chemical and mechanical engineering.The discovery that carbon nanotubes (CNT) and RTILs can be blended to form gels termed as "Bucky gels" which can potentially be used in many engineering or chemical processing such as making novel electronic devices, coating materials, and antistatic materials and thus, it opens a completely new field [51,52]. The "Bucky gels" are blends or emulsions of ILs with nanomaterials, mostly nanocarbons (tubes, fullerenes, and spheres) and they are actually CNT laden IoNanofluids. The possibility of using ionic liquids containing dispersed nanoparticles with specific functionalization such as functionalized single-walled nanotubes (SWCNT), multi-walled nanotubes (MWCNT) and fullerenes (C60, C80 etc.) opens the door to many applications. In recent reviews the authors have shown the properties of the IoNanofluids and nanofluids and highlighted their possible applications in different areas [9,53-55].

\subsection{Manufacture of IoNanofluids}

Although significant progress has been made in the last years, variability in the heat transfer characteristics of the nanofluids so far reported is presented, with very different thermal conductivity enhancements for the same systems. This variability may be the result of the various synthetic techniques employed, and the purity of the starting materials. The manufacture of nanofluids is delicate, as it does not mean necessarily a simple mixture of solid particles and a liquid, in the thermodynamic definition, and the techniques used by different authors are sometimes ill-defined [37,56].

Thus the synthesis of IoNanofluids can be a delicate operation. There are two main techniques used with normal solvents, the two-step process and the direct evaporation technique or single step. Most researchers use the two-step process, by dispersing commercial or selfproduced nanoparticles in the liquid, a technique that can create large particle agglomerates, which can be destroyed by adding surfactants or using mechanical or ultrasound dispersion techniques.However the synthesis in situ seems to be the most efficient to produce very homogeneous particles, with a narrow size distribution, originating long period stability, especially for metal nanoparticles $[57,58]$. Aida and co-workers found that imidazolium-cationbased ionic liquids were excellent dispersants for CNT's, forming physical gels, that could be reproduced using sonication or by grinding the suspension in an agate mortar with a pes-

2 The thermal conductivity of molecular, organic and inorganic liquids, with the exception of molten metals, ranges from 0.1 to $0.6 \mathrm{Wm}-1 \mathrm{~K}-1$. 
tle. These techniques were followed by the current authors groups, to obtain very stable emulsions, without surfactants, with 0-3\% (w/w) loading of MWCNTs (Multi-walled carbon nanotubes) in a range of imidazolium and pyrrolidinium ILs.

The importance of the purity of both starting materials and the technique used for manufacturing the dispersed nanomaterial is very important. In first place, the ionic liquid must be as pure as possible, as small quantities of water can affect its properties [59], and subsequently those of the Ionanofluid. Although the preparation of the dispersions is made open to atmosphere and therefore capable of introducing water in the samples, these were monitored by Karl-Fisher Coulometric analysis, and the amount of water in the pure ionic liquids never exceeded $400 \mathrm{ppm}$ before the measurements and $800 \mathrm{ppm}$ after the measurements, values that do not affect the thermal conductivity measurements [60].

The properties and characteristics of the nanomaterials are an extremely important issue. Most of the nanomaterials are spherical, rod or oblong in shape. Current manufacturing procedures can result in batch to batch variability as the degree of outer shell nanomaterial functionalization caused during manufacture and geometries of the nanomaterials can change $^{3}$. One such example is in the case for silver nanoparticles, where $80 \%$ of the manufacturers use polymer coatings of non-disclosed thickness and properties. These coatings determine completely the heat transfer properties of the nanomaterials, and if we want to use silver nanoparticles they have to be chemically treated to eliminate them. Many publications on nanofluids systems previously reported were probably not aware of these problems and therefore those results have to be confirmed.

Our current experience in Ionanofluid manufacture is based on MWCNTs, and therefore we restrict our analysis to IoNanofluids based on these nanomaterials. However several studies are currently in progress using $\mathrm{TiO}_{2}$ and Ag spherical particles, as well as nanomaterials delivered from nature [9,61-63].

The IoNanofluids based on MWCNTs must obey the following conditions: homogeneous dispersion, stable over a great period of time (not producing phase separation, even at a micro scale), and be free of additives, such as surfactants or salts. In addition, one of envisaged applications involves their use as heat transfer fluids, a control of viscosity is crucial, in order to create fluids with sensible heat transfer coefficients in dynamic regime (good fluidity). The preparation procedure involves weighing the nanomaterial, addition to the ionic liquid and introduction into the sonicator cell. Optimization of the time and sonication energy, visual observation for phase separation of the IL from the Ionanofluid is crucial ${ }^{4}$. Excessive time and high energy can result in the break-up of the Ionanofluid and breakage of tube walls. Moreover, impurities in the glass cells can lixiviate them and introduce further elements into the dispersion. The IoNanofluids dispersions produced are then allowed to settle several hours before the thermophysical properties measurements. The existence in micro-

\footnotetext{
3 In a majority, the producers of nanoparticles do not disclose the real structure of the particles, the presence of polymer coatings or oxidative type reactions

4 The dispersion is black, as shown in Figure 4. Therefore a great care as to be taken in the observation, helped by reflected light analysis through the suspensions
} 
phase separation is controlled by measuring the properties of the dispersion, in several occasions. As an example, for thermal conductivity, dispersions in $\left[\mathrm{C}_{2} \mathrm{mim}\right][\mathrm{dca}]$, were measured within an interval of one year and their values did not differ by more than $2 \%$, well within the uncertainty of the measurements [60]. Figure 4 illustrates the main steps for the preparation, starting with the ionic liquid, adding the carbon nanotubes, using the sonicator probe and finally the dispersion.

\subsection{Experimental properties and their impact on process equipment design}

As described above, the most important thermophysical properties for heat exchange equipment design are thermal conductivity, heat capacity, density and viscosity. They control the dynamics of heat transfer, namely the heat transfer coefficients and the heat transfer areas of the exchangers. In order to decide if any fluid can be used as an alternative to current engineering fluid, there are two essential questions to answer:

1. Are the properties of the fluid adequate to the process(es) where it will be used?

2. If the answer to the first technical question is affirmative, is the fluid economic competitive?

The answer to the first question raises another two problems: a) how accurate the thermophysical property data available is and b) what is the sensitivity of the main design parameters in heat exchange (heat transfer area, flow rates, pressure drops) are affected by the uncertainty of those properties. These factors will be discussed in detail below.

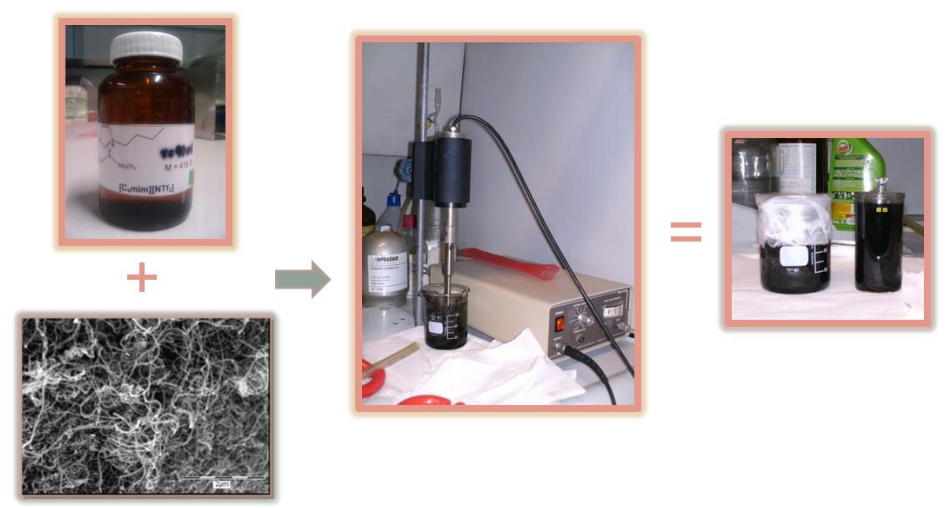

Figure 4. Main steps for the preparation of IoNanofluids with MWCNTs.

The determination of experimental values of the thermophysical properties of ionic liquids has been discussed in two recent reports, regarding the methods of measuring (existing and foreseen new developments) and how important is to characterize the samples in order to trust the measurements made with the highest accuracy available [59,64].This fact, using ionic liquids as base fluids for the nanofluids, is very important as they can absorb water 
from the environment. As an example, Table 1 shows the results obtained for 3 ionic liquids in our laboratory, which were used for IoNanofluids preparation [60]. The ILs were obtained from Io-Li-Tec, DE, dried under vacuum for several days at approximately $60^{\circ} \mathrm{C}$ and the water content was determined with a Karl-Fisher Coulometer.

The effect on the measured values of the properties depends on these, being more significant for viscosity [65,66]. For thermal conductivity an effect of $1000 \mathrm{ppm}(0.02$ in the molar fraction of the mixture), the maximum effect at $70^{\circ} \mathrm{C}^{5}$ is $0.2 \%$ (much smaller than measurement uncertainty). These results show that it is very important to characterize the samples, determining its water content, before and after the measurements, a fact that has not been recognized so far by many authors and journal editors.

The methods used to measure the thermophysical properties have also to be well characterized: many deviations between data obtained by different methods and different laboratories are caused by ill-defined measuring methods [59,64]. It is not the purpose of this review to describe the best experimental systems, as a full discussion was presented before [64]. However the readers should be attentive to this problem. It is very tempting for some research group that enters the field of ionic liquids to use equipments already available, using measuring cells that sometimes are not adequate. In addition the availability on the market of reliable measuring instruments also creates an opportunity for "fast" data production.

\begin{tabular}{lrrrr}
\hline lonic Liquid & $\begin{array}{l}\text { Manufacturer } \\
\text { Purity / \% }\end{array}$ & $\begin{array}{l}\text { Manufacturer } \\
\mathbf{H}_{\mathbf{2}} \mathbf{O} / \mathbf{~ p p m}\end{array}$ & $\begin{array}{l}\text { After Drying } \\
\mathbf{H}_{\mathbf{2}} \mathbf{O} / \mathbf{~ p p m}\end{array}$ & $\begin{array}{l}\text { After Measurements } \\
\mathbf{H}_{\mathbf{2}} \mathbf{O} / \mathbf{~ p p m}\end{array}$ \\
\hline$\left[\mathrm{C}_{2}\right.$ mim] $[\mathrm{dca}]$ & $>98$ & 1850 & $234.7 \pm 48.6$ & $488.9 \pm 58.6$ \\
\hline$\left[\mathrm{C}_{4}\right.$ mim] $[\mathrm{dca}]$ & $>98$ & 1480 & $324.9 \pm 86.4$ & $683.6 \pm 41.7$ \\
\hline$\left[\mathrm{C}_{4} \mathrm{mpyr}\right][\mathrm{dca}]$ & $>98$ & 1710 & $349.6 \pm 47.9$ & $637.0 \pm 57.0$ \\
\hline
\end{tabular}

Table 1. Water content of 3 ionic liquids, before and after the thermal conductivity measurements

Other factors are known to affect the determination of experimental values, not strictly dependent of the instrumental methods used. For example the compatibility of ILs with seals, gaskets and metals contained in the measuring cell is very important. Ionic liquids anions and cations can be very different in size and to date most of the existing information has been obtained for imidazolium cations, making it difficult to generalize for other non-imidazolium ionic liquids. These ions are not mutual independent, can form aggregates and complicate structures in the liquid phase. In addition the viscosity is moderate to high, the liquids are electrical conducting and the heat capacity per unit volume is rather high. All these factors condition heat and mass transfer in the transport properties determination and must be known "a priori" to avoid systematic errors.

An example selected from reference [64] is sufficient to illustrate the point about "bad" and good" measurements. Figure 5 shows the heat capacity of $\left[\mathrm{C}_{4} \mathrm{mim}\right]\left[\mathrm{BF}_{4}\right]$, obtained using DSC

5 The effect decreases the value of the thermal conductivity and increases with temperature 
[67-73]. A wide variation between the datasets of up to $20 \%$ at room temperature is observed. This situation is very uncommon in calorimetry; however it is known that, apart from differences in sample purity, the DSC used must be well calibrated before use, a fact which could also help to explain the scatter of data. However, it can be seen [50] that 5 sets of data agree within $2 \%$, within their mutual uncertainties $[50,67,68,72,73]$, a result that would be considered excellent for DSC data, the most popular measuring method, due to its speed and excellent repeatability. Bearing in mind that handling and measuring ILs physical properties is not trivial, the authors would like to recommend a careful analysis of all these aspects prior to making measurements and reporting data.

The second point to analyze is how the sensitivity of the main design parameters in heat exchange (heat transfer area, flow rates, pressure drops) are affected by the uncertainty of those properties. This was the subject of many publications in the past, and recently we have applied this to ionic liquids. Using the same methodology [74], analyzing the effect of the uncertainty of thermophysical data of ionic liquids (density, heat capacity, thermal conductivity and viscosity) in the design of some current equipment, used in processes as solvents or heat transfer fluids. Data has been collected from IL Thermo database [75] for alkylmethylimidazolium, $\left[\mathrm{C}_{\mathrm{n}} \text { mim }\right]^{-}$liquids, with $\left[\mathrm{BF}_{4}\right]^{-}$and $\left[\mathrm{PF}_{6}\right]^{-}$anions. This was justified by the fact that the thermophysical properties of ionic liquids, measured in different laboratories and by different methods do not agree within their mutual uncertainties. This was probably caused by incorrect methods of measurement and/or purity problems, as stated above. Results obtained show that the influence of actual errors in the thermophysical properties of ionic liquids can render any future design of chemical plant equipment as not working or excessively costing. Although the actual cost of ionic liquids is higher than conventional heat transfer fluids, the future production of higher quantities can make their use competitive, especially if a target price of $25 \mathrm{US} \$ / \mathrm{kg}$ is achieved.

The heat storage capacities of $\left[\mathrm{BF}_{4}\right]^{-}$and $\left[\mathrm{PF}_{6}\right]^{-}$and other ionic liquids, containing anions like $\left[\mathrm{C}_{2} \mathrm{H}_{5} \mathrm{SO}_{4}\right],\left[\left(\mathrm{CF}_{3} \mathrm{SO}_{2}\right)_{2} \mathrm{~N}\right],\left[\mathrm{CF}_{3} \mathrm{SO}_{3}\right]$ and $\left[\mathrm{C}_{8} \mathrm{H}_{17} \mathrm{SO}_{4}\right]$, which can be considered as possible replacements of current heat transfer fluids, have been analyzed. A comparison with the properties of synthetic compounds (based on hydrocarbons, polyaromatics and siloxanes), showed that common imidazolium IL systems have higher heat capacities per unit volume than high performance commercial thermal fluids, such as Paratherm HE(a registered mark of Paratherm Corporation) and Syltherm $800^{\mathrm{TM}}$, Syltherm HFT Dowtherm $\mathrm{A}^{\mathrm{TM}}$ and Dowtherm MX ${ }^{\mathrm{TM}}$ (trademarks of Dow Chemical Company, USA) [75]. Details of the methodology application can be found in this reference. The analysis was limited to study the effect of the uncertainty in the properties in the major design parameter, the heat transfer area, in a preselected heat transfer equipment, a shell and tube heat exchanger, as it reflects the changes in the design arising from the changes in the thermophysical properties of the ionic liquid process stream. This also permits a more facile estimation of the economic consequences of these changes in the design. 


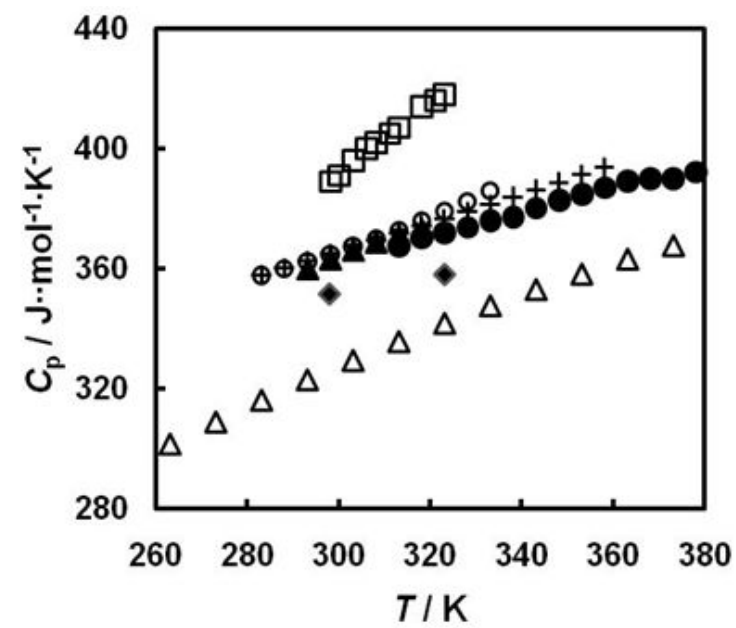

Figure 5. Existing values of the heat capacity for $\left[\mathrm{C}_{4} \mathrm{mim}\right]\left[\mathrm{BF}_{4}\right]$ as a function of temperature (2010). - Nieto de Castro et al. [50]; - Van Valkenburg et al. [67]; - Rebelo et al.[68]; - Kim et al.[69]; - Fredlake et al. [70]; - Waliszewski et al. [71]; Garcia-Miaja et al. [72]; - Garcia-Miaja et al. [73].

The equipment chosen is one modern solar power plant that uses a molten salt receiver as thermal energy storage system, which captures the sun's energy and stores it in hot molten sodium nitrate or molten nitrates mixtures, so that power can be generated when needed, not just when the sun is shining. The heat transfer unit uses a molten salt through oil to salt heat exchanger [76,77]. The molten salt mixture used was replaced by a ionic liquid, one set of reference conditions for the operation were chosen based on a given set of values of the thermophysical properties and then the assigned values were perturbed about their reference values, within ranges commensurate with the actual stage of experimental uncertainty reported in IL Thermo database [75]. The effect of the uncertainties of the thermophysical properties of the ionic liquids can be calculated by calculating the new heat transfer area $A_{0}$ and its variation $A$ as a function of the variation in percentage of the thermophysical properties, $, \Delta \mathrm{Q}, \Delta \eta, \Delta \lambda$ and $\Delta \mathrm{C}_{\mathrm{P}}$. Figure 6 shows in a $3 \mathrm{D}$ plot the effect of $\Delta \mathrm{C}_{\mathrm{P}}$ and $\Delta \lambda$ in $\Delta \mathrm{A}$ for $\left[\mathrm{C}_{2} \mathrm{mim}\right]$ $\left[\mathrm{BF}_{4}\right]$, using again the viscosity uncertainty, $\Delta \eta$ as a parameter for the surfaces. The density is not shown, as this is the property known with less uncertainty. Not using extreme values, whereby the area can be overestimated by $50 \%$, an error of $+20 \%$ in viscosity, $-20 \%$ in thermal conductivity and $-10 \%$ in heat capacity generates an error of $+20 \%$ in the area of the heat exchanger.

From the results presented we can conclude that the effects of the uncertainty in the thermophysical properties of RTIL's are high and that the heat transfer areas (see Table 2) are higher than those obtained with the used heat transfer oils. The exception to this is $\left[\mathrm{C}_{2} \mathrm{mim}\right]\left[\mathrm{BF}_{4}\right]$. These effects can render equipment obsolete and/or induce additional operational costs, well above of those estimated by design. When a heat exchanger is built, its cost will be weakly dependent on the size/length of the pipes, but highly dependent on the heat transfer area 
and the operational costs will increase significantly with size. However, to increase the capacity of the unit after having been built would represent an additional cost, possibly smaller than replacing it with a new unit. Therefore, the wise approach would be to obtain good experimental measurements of the heat transfer used, as described above.

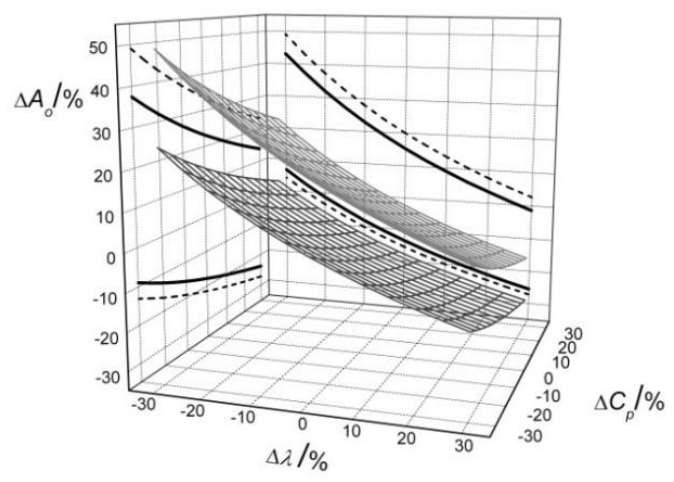

Figure 6. 3D plot of the effect of uncertainty of heat capacity $\left(C_{p}\right)$ and thermal conductivity () for $\left[C_{2} m_{i m}\right]\left[B F_{4}\right]$ on the area (A) of a shell and tubes heat exchanger, using viscosity uncertainty, , as a parameter for the surfaces (upper, +20 $\%$; lower, $-20 \%)$; the lines in the planes represent the maximum and minimum values of the area variation for \pm 20 $\%$, and $\pm 30 \%$, ---, in $\Delta \lambda$ and $\Delta C_{p}$. Adapted from [74].

In order to determine whether ionic liquids are economic as practical heat transfer fluids the costs of heat transfer equipment need to be examined. Details of the cost estimation of the heat exchanger can be found in [75]. The total cost required for a new design can be broken in five parts [84], the battery limits investment, the utility investment, the off-site investment, the engineering fees and the working capital. From these, we were concerned first with the battery limit investment, which is the cost of individual plant items and their installation to form the working process. The cost of the heat exchanger will be a function of its size (were the type of heat exchanger and the heat transfer area are critical), the materials of its construction (materials compatibility between metal parts and heat transfer fluids), design pressure and temperature, and it can be given by:

$$
C_{\mathrm{E}}=C_{\mathrm{B}}\left(\frac{X}{X_{\mathrm{B}}}\right)^{m} f_{\mathrm{M}} f_{\mathrm{P}} f_{\mathrm{T}}
$$

where $C_{E}$ represents the cost of the equipment with a given capacity $X$ (here the heat transfer area, $\left.A_{0}\right), C_{B}$ the base cost of a reference equipment with a capacity $X_{B}$, and $m$ a constant depending of the equipment type ( $m=0.68$ for a shell and tube heat exchanger). The base cost of a carbon steel shell and tube heat exchanger, with a heat transfer area of $80 \mathrm{~m}^{2}$ would be $3.2810^{4}$ US\$. $f_{M}$ is the correction factor for materials of construction different from carbon 
steel, $f_{P}$ the correction factor for design pressure and $f_{T}$ the correction factor for design temperature. Values used for these factors can be found in references [74, 84].

The results obtained for the estimated costs for the shell and tube heat exchangers using the different heat transfer fluids are shown also in Table 2. Keeping other factors constant the heat exchangers for the $\left[\mathrm{PF}_{6}\right]^{-}$based RTIL's are significantly more expensive that the conventional fluids. However $\left[\mathrm{C}_{2} \mathrm{mim}\right]\left[\mathrm{BF}_{4}\right] \mathrm{IL}$ is only moderately more expensive. Depending on the process, it may be possible to obtain savings in the ILs equipment, either by changing other design variables $\left(D_{e}, D_{i}\right.$, pressure drops, materials, temperatures of the cold and hot streams, etc.,) or, by using other ionic liquids than the ones tested, especially those ILs with lower viscosity values. In addition, the cost of ionic liquids, which is currently in the order of $100-500 \mathrm{US} \$ / \mathrm{kg}$ for research due to high value of the personnel costs involved at this scale, are now evolving for industrial production to targeted prices of $25 \mathrm{US} \$ / \mathrm{kg}$ [85], a value which makes them valuable alternative heat transfer fluids, from the economic side. For example, the ionic liquid $\left[\mathrm{C}_{2} \mathrm{mim}\right]\left[\mathrm{EtSO}_{4}\right]$ is now available on an tonne scale, from Solvent Innovation $\mathrm{GmbH}$, Cologne (www.solventinnovation.de) or BASF AG (www.basionics.de).

\begin{tabular}{|c|c|c|c|c|c|c|}
\hline $\begin{array}{l}\text { Heat Transfer } \\
\text { Fluid }\end{array}$ & $\begin{array}{c}\rho \\
/ \mathrm{kgm}^{-3}\end{array}$ & $\begin{array}{c}C_{P} \\
/ \mathrm{Jkg}^{-1} \mathrm{~K}^{-1}\end{array}$ & $\eta / m$ Pas & $\begin{array}{c}\lambda \\
\left.\mathrm{mW} \mathrm{m}^{-1} \mathrm{~K}^{-1}\right)\end{array}$ & $\begin{array}{c}A_{0} \\
/ \mathrm{m}^{2}\end{array}$ & $\begin{array}{l}C_{E} \\
/ \mathrm{k} \$\end{array}$ \\
\hline $\begin{array}{c}{\left[\mathrm{C}_{4} \mathrm{mim}\right]\left[\mathrm{PF}_{6}\right]} \\
\left(50^{\circ} \mathrm{C}\right)\end{array}$ & $1346 \pm 1^{83}$ & $1493 \pm 30^{79}$ & $68.8 \pm 1.8^{83}$ & $146 \pm 7^{81}$ & 480.75 & 738 \\
\hline $\begin{array}{c}{\left[\mathrm{C}_{6} \mathrm{mim}\right]\left[\mathrm{PF}_{6}\right]} \\
\left(50^{\circ} \mathrm{C}\right)\end{array}$ & $1273 \pm 3^{78}$ & $1409 \pm 61^{79}$ & $111.9 \pm 3.2^{80}$ & $146 \pm 7^{81}$ & 634.60 & 891 \\
\hline $\begin{array}{c}{\left[\mathrm{C}_{2} \mathrm{mim}\right]\left[\mathrm{BF}_{4}\right]} \\
\left(50^{\circ} \mathrm{C}\right)\end{array}$ & $1280 \pm 2^{78}$ & $1600 \pm 25^{67}$ & $15.9 \pm 1.1^{82}$ & $196 \pm 6^{67}$ & 217.29 & 430 \\
\hline $\begin{array}{c}\text { Dowtherm } A^{\mathrm{TM}} \\
\left(50^{\circ} \mathrm{C}\right)\end{array}$ & 1041 & 1632 & 2.12 & 134 & 138.60 & 317 \\
\hline $\begin{array}{c}\text { Dowtherm } \mathrm{MX}^{\mathrm{TM}} \\
\left(100^{\circ} \mathrm{C}\right)\end{array}$ & 905 & 1870 & 2.09 & 114 & 159.08 & 348 \\
\hline $\begin{array}{l}\text { Syltherm } 800^{\mathrm{TM}} \\
\qquad\left(80^{\circ} \mathrm{C}\right)\end{array}$ & 882 & 1711 & 3.86 & 124 & 202.86 & 410 \\
\hline $\begin{array}{l}\text { Syltherm } \mathrm{HF}^{\mathrm{TM}} \\
\left(80^{\circ} \mathrm{C}\right)\end{array}$ & 811 & 1830 & 0.83 & 92 & 135.47 & 312 \\
\hline
\end{tabular}

Table 2. Values of Heat Transfer Liquids Properties, Reference Area $A_{0}$ and Estimated Costs for the Shell and Tube Heat Exchanger

For IoNanofluids, there is only one study, still unpublished, performed in Lisbon laboratory [86], with $\left[\mathrm{C}_{4} \mathrm{mim}\right]\left[\mathrm{NTf}_{2}\right]$ and $\left[\mathrm{C}_{2} \mathrm{mim}\right]\left[\mathrm{EtSO}_{4}\right]$ and MWCNTs. As no data is available for the heat capacity and viscosity enhancements ${ }^{6}$, we have assumed for the corresponding enhancements $E_{\lambda}=E_{\eta}, E_{C p}=1.5 ; 2 ; 5 \%$ and $E_{\rho}=0$. Figure 7 shows the variation in the area $\mathrm{A}$ of 
the same heat exchanger as a function of the volume fraction of the Ionanofluid ${ }^{7}$. The data points are labeled to show the values of the areas obtained. The maximum enhancements in the thermal conductivity were found for the $3 \% \mathrm{w} / \mathrm{w}$ IoNanofluids, around $25 \%$ for $\left[\mathrm{C}_{4} \mathrm{mim}\right]$ $\left[\mathrm{NTf}_{2}\right]$. The effect, only of the thermal conductivity enhancement can be as much as $20 \%$ decrease in the area, and therefore in the cost of the heat exchanger, saving about US\$ 20 mfor a $20 \%$ volume fraction of MWCNT ( $3 \% \mathrm{w} / \mathrm{w})$, a value very significant. Progress in the experimental measurement of density, heat capacity and viscosity of these IoNanofluids will be reported soon.

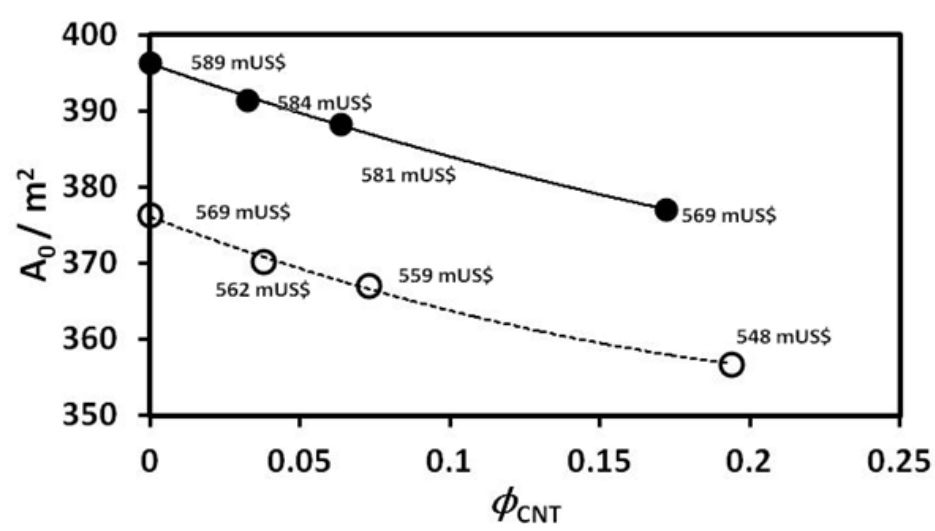

Figure 7. $A_{\circ} \mathrm{vS}_{\mathrm{CNT}}$ for ionic liquids and loNanofluids. - fluids based on $\left[\mathrm{C}_{4} \mathrm{mim}\right]\left[\mathrm{NTf}_{2}\right]_{;}$- fluids based on $\left[\mathrm{C}_{2} \mathrm{mim}\right]\left[\mathrm{EtSO}_{4}\right]$. Close to each data point is the cost of the heat exchanger, in US\$.

\subsection{Other process requirements}

There are a number of factors that have to be considered to make the possible the use of these IoNanofluids in industry. We restrict the discussion associated with the analysis of thermal stability and toxicity.

\subsubsection{Thermal stability}

The thermal stability of the IoNanofluids has two major components: the thermal stability of the ionic liquid base fluid and the thermal stability of the dispersion, on a long term. These are facts that have to be studied. In the case of ionic liquids there is already a substantial amount of information that allow us to be confident that it is easy to target an operational value of $200^{\circ} \mathrm{C}^{8}$, especially for the liquids mentioned in this review. However, ionic liquids

7 As the densities of the carbon nanotubes are much smaller than those of the base fluids, the volume fraction is much greater than the weight fraction $(0.5,1,3 \%)$

8 In a great majority of chemical processes, temperatures for heat transfer above $200^{\circ} \mathrm{C}$ are not used, for energy cost reasons 
have the tremendous advantage of being target designed, so there will be always the possibility of synthesizing a new high temperature ionic liquid. However the thermal stability of the IoNanofluids is a totally different game, as the homogeneous system can be transformed in a heterogeneous phase, with micro phase equilibria, promoting aggregation of the nanomaterials and/or phase separation, at a micro or macroscopic level. In principle, the increase in temperature will facilitate the homogeneous system, due to the increase in entropy of the base fluid. No data is yet available for temperatures above $70^{\circ} \mathrm{C}$, so any further conclusion will be premature. New studies in this area are needed.

\subsubsection{Toxicity of ionic liquids, nanomaterials and IoNanofluids}

Regarding toxicity, there are not any studies for IoNanofluids, and none to date for nanofluids. In the absence of any additional effect, the toxicity of an Ionanofluid will be a sum of the toxicity of the base ionic liquid and that of the nanomaterial used. For ionic liquids, our current knowledge is still scarce, and without long term consequences, but some conclusions can already been suggested $[87,88]$. Following the extensive review by Petkovic et al. [87], "it is clear that the numerous formulations of ionic liquids available provide a great pool of, and impetus for, many commercial applications, but not without significant toxicological and environmental concerns. The vast majority of toxicological studies on ionic liquids, available up to the present date, have focused on imidazolium ionic liquids. In addition, frequently, the ionic liquids "selected" for study tackled under a common assay were randomly chosen. Despite the scientific weight of these studies, the lack of systematisation (e.g. monitoring the effect of defined structural alterations in a specific head group) means that it is impossible at the moment to achieve a holistic analysis, which weakens conclusions and devalues the predictive algorithms under development."(citation) Some problems regarding the selection of the bioassay, namely subjectivity and regional-orientation restrict generalizations. Legislation demands and standardised tests should be kept as a priority, engaging models of different complexity. The environmental persistence of any chemical should be taken as one of the most critical ecotoxicological parameters [88].

The European Community regulation on chemicals and their safe use-REACH (Registration, Evaluation, Authorisation and Restriction of CHemical substances) - [89] aims to increase the awareness of the industry on hazards and risk management. REACH registration, in force since 2007 , is mandatory for any chemical produced in the quantity over one tonne per year. Although it is being criticised for itsever-increasing cost and the number of animals employed intesting, [90] REACH undoubtedly provides a meaningful, and necessary, framework to raise human and environmental safety. Currently, only the ionic liquids which have already found application on industrial scale are undergoing REACH registration. As an example, as $\left[\mathrm{C}_{2} \mathrm{mim}\right][\mathrm{X}]\left(\mathrm{X}=\mathrm{Cl}^{-},\left[\mathrm{C}_{2} \mathrm{SO}_{4}\right]^{-},\left[\mathrm{C}_{1} \mathrm{SO}_{3}\right]^{-},\left[\mathrm{O}_{2} \mathrm{CMe}\right]^{-}\right.$and $\left.\left[\mathrm{NTf}_{2}\right]^{-}\right)$and $\left[\mathrm{C}_{4} \mathrm{mim}\right][\mathrm{Cl}]$ [91], but there are nodoubts that this number will continuously increase.It appears, however that the cytotoxicity of ionic liquids cannot be systematically estimated by a summation of the independent effects of the cation and anion [92, 93]. Moreover, mixtures (binary or ternary) of ionic liquids have been rarely investigated [94]. 
The next components of IoNanofluids to be analysed are the nanomaterials used. However the toxicity of nanomaterials, although present in small mass content in the IoNanofluids, raises several problems and requires certain rules to be obeyed.

First, the nanomaterials dispersed in the IL have different chemical and physical properties than those of bulk materials of identical composition. It is then reasonable to expect that the biological properties of nanomaterials are different as that of bulk materials. Secondly, nanomaterials may be unique in environmental or biological systems. The properties of a nanoparticle in nonpolar solvents change when extracted into the aqueous phase; furthermore, nanoparticles in biological fluids (buffered solutions, cell culture media, or blood) may behave differently, as well. The nanoparticle surface is the part of the nanoparticle system that will have direct interactions with the biological entity (as with the ionic liquid); therefore, the surface of the nanoparticle will influence the biological response. Finally, a full characterization profile of the nanoparticles system being tested in biology must be reported [95].

The identity of the nanoparticle sample must be known in order to accurately report the positive, negative, or neutral effects of nanoparticles in vitro or in vivo. National and international standards committees (such as International Organization for Standardization, American Society for Testing and Materials, and International Council on Nanotechnology) have begun to establish recommendations for adequate nanomaterial physicochemical characterization data relevant to toxicology. These recommendations come from the literature of a variety of disciplines, including biological, environmental, and material sciences [96-98].

There are a few key points that the growing body of nanotoxiciology literature has taught us. First, morphological characterization, such as particle size and shape, should be measured in the most dispersed state achievable. Second, ideally, particle characterization data should be measured under conditions as close to the point application as possible a property should be measured using more than one method. The successful development of safe nanomaterials requires a strong collaborative effort between toxicologists, physical scientists and engineers. All characterization data should be validated using multiple techniques. Scientists from chemistry, biology, and engineering backgrounds must work together to address issues related to the potential impacts of nanomaterials, nanocomposites, and nanoparticle-containing consumer and medicinal products on the environment, human health, and even the synthesis and manufacture of nanomaterials. The ultimate goal of this collaborative effort is to determine the effects of nanomaterials in environmental and biological systems [95].

One key property essential to an understanding of the responses between nanomaterials and biological systems is the interaction between cells and the surface of the nanoparticle.

Primary characterization is performed on particles as-synthesized or as-received: in its dry native state. Secondary characterization is performed on particles in the wet phase as a solution or suspension in aqueous media. This media could be in ultrapure water, vehicle solution, or cell culture media (prokaryotic or eukaryotic). Physical and chemical characterization relevant to toxicity testing includes size and size distribution (including aggregation/agglomeration/coagulation state), concentration and purity, surface activity/reactivity, particle composition of surface coatings. Tertiary characterizations are performed on particles following interactions with cells under in vivo or in vitro conditions, and imaging 
the nano-bio interface. Characterization data and functionality information of nanoparticles suspended in serum, media, buffers, or other biological fluids may be different than data gathered in water. Determining the toxic effect of a nanomaterial is a challenging endeavour because each study requires a comprehensive material characterization component (which includes both physical and chemical properties) and adequate toxicological evaluation (relevant to the hypothesized route of exposure and eventual biological fate) [99].

It is difficult to produce nanomaterials on a large scale, because the mass of material produced is very small. One gram of nanoparticles is approximately equivalent to one billion particles. The immediate challenge of toxicological studies of nanoparticles is not only producing enough material for a complete in vivo study, but to also produce enough material for characterization purposes. Therefore, both new toxicological testing and characterization methods are needed when tackling this problem. New methodologies, as well as, standardization of common techniques are needed within the realm of determining the safety of nanomaterials $[95,100]$.

Finally this problem must be tackled as a logical sequence from laboratory synthesis to industrial production. The priority aspects will be the ecological, human health, and waste elimination besides the costs of the full operation, as the functionalities of IoNanofluids are many and extremely varied. The most important parameter to be considered is the interference parameter for the mixtures (interfacial behaviour), a logic consequence of the primordial role of the nanomaterial - IL interaction [96]. A wide range of physicochemical properties are relevant to toxicology, like particle size distribution, morphology, chemical composition, solubility and surface chemistry and reactivity [95]. Not a single method can be used, but combinations of standard tests have to devise.

Some authors state that the surfactant may cause physical and/or chemical instability problems. The use of surfactants or any other additives to stabilize the microemulsions of the nanofluids can be worse than the nanomaterials and ionic liquids $[99,100]$.

A new network of existing infrastructures to ensure a cost-effective and time-efficient examination of health, safety, and environmental aspects of nanomaterials throughout Europe and linking effectively with other international related activities is urgently needed, through European Chemical Agency, ECHA [101].

\section{Theoretical Modelling of Nano and IoNanofluids}

Since nanofluids were found to exhibit anomalously high thermal conductivity which cannot be predicted by the existing classical models, based on macro and nanoscale mechanisms numerous theoretical models for nanofluids have been developed over the last decade [37]. However, most of these models are neither validated with wide ranges of nanofluids systems nor accepted widely. On the other hand, no theoretical model so far is available (to the best of our knowledge) for the prediction of thermal conductivity of this newly emerged IoNanofluids. Thus, in an attempt to predict the effective thermal conductivity of IoNanofluids, representative classical model as well as recent models are used here. 
The effective thermal conductivity of suspensions of milli- or micro-sized solid particles can be predicted by numerous classical models like the most popular Maxwell [102] and Hamilton-Crosser [103] models. The Maxwell model for the effective thermal conductivity $\left(\lambda_{\text {eff }}\right)$ of suspensions of spherical inclusions can be expressed as [102]:

$$
\lambda_{\text {eff }}=\lambda_{\mathrm{f}}\left[\frac{\lambda_{p}+2 \lambda_{\mathrm{f}}+2 \phi_{p}\left(\lambda_{p}-\lambda_{\mathrm{f}}\right)}{\lambda_{p}+2 \lambda_{\mathrm{f}}-\phi_{p}\left(\lambda_{p}-\lambda_{\mathrm{f}}\right)}\right]
$$

where $\phi_{\mathrm{p}}$ is the particle volume fraction, and ${ }_{\mathrm{f}}$ and ${ }_{\mathrm{p}}$ are the thermal conductivities of the base fluid and particle, respectively.

The Maxwell model [102] was later modified by Hamilton and Crosser [103] for the effective thermal conductivity of both the spherical and non-spherical particles by using a shape factor. Their model is a function of the thermal conductivities of both solid and liquid phases, volume fraction, and the shape of the disperse particles. The Hamilton-Crosser model [103] has the form:

$$
\lambda_{\text {eff }}=\lambda_{\mathrm{f}}\left[\frac{\lambda_{p}+(n-1) \lambda_{\mathrm{f}}-(n-1) \phi_{p}\left(\lambda_{\mathrm{f}}-\lambda_{\mathrm{p}}\right)}{\lambda_{p}+(n-1) \lambda_{\mathrm{f}}+\phi_{p}\left(\lambda_{\mathrm{f}}-\lambda_{p}\right)}\right]
$$

where the shape factor $n=3$ for spherical particles and $n=6$ for cylindrical particles. For spherical particles, Eq.(3) reduces to Eq.(2).

Most of the researchers working on nanofluids [37] found these classical models are unable to predict the anomalous thermal conductivity of nanofluids. Therefore, many theoretical studies have been carried out to understand the heat transfer mechanism and to develop models for predicting the effective thermal conductivity of nanofluids [37]. Among a handful of efforts, by taking into account the effects of particle size, concentration, and interfacial nanolayer two models for the prediction of thermal conductivity of nanofluids $\left(\lambda_{\text {eff-nf }}\right)$ containing spherical and cylindrical nanoparticles were developed by Murshed et al. [36]. The model for suspensions of spherical nanoparticles is expressed as [36]:

$$
\lambda_{\text {eff-nf }}=\lambda_{\mathrm{f}} \frac{\phi_{p} \omega\left(\lambda_{p}-\omega \lambda_{\mathrm{f}}\right)\left[2 \gamma_{1}^{3}-\gamma^{3}+1\right]+\left(\lambda_{p}+2 \omega \lambda_{\mathrm{f}}\right) \gamma_{1}^{3}\left[\phi_{p} \gamma^{3}(\omega-1)+1\right]}{\gamma_{1}^{3}\left(\lambda_{p}+2 \omega \lambda_{\mathrm{f}}\right)-\left(\lambda_{p}-\omega \lambda_{\mathrm{f}}\right) \phi_{p}\left[\gamma_{1}^{3}+\gamma^{3}-1\right]}
$$

where $\omega=\lambda_{\mathrm{lr}} / \lambda_{\mathrm{f}^{\prime}} \gamma=1+t / r_{p}, \gamma_{1}=1+t /\left(2 r_{p}\right), r_{p}$ is the radius of the particle, $t$ and $\lambda_{\mathrm{lr}}$ are the thickness and the thermal conductivity of interfacial nanolayer, respectively. On the other hand, model for the cylindrical nanoparticles has the form [36]:

$$
\lambda_{\text {eff-nf }}=\lambda_{\mathrm{f}} \frac{\phi_{p} \omega\left(\lambda_{p}-\omega \lambda_{\mathrm{f}}\right)\left[\gamma_{1}^{2}-\gamma^{2}+1\right]+\left(\lambda_{p}+\omega \lambda_{\mathrm{f}}\right) \gamma_{1}^{2}\left[\phi_{p} \gamma^{2}(\omega-1)+1\right]}{\gamma_{1}^{2}\left(\lambda_{p}+\omega \lambda_{\mathrm{f}}\right)-\left(\lambda_{p}-\omega \lambda_{\mathrm{f}}\right) \phi_{p}\left[\gamma_{1}^{2}+\gamma^{3}-1\right]}
$$

Although the thickness of nanolayer $(t)$ is considered to be $1 \mathrm{~nm}$ [36], the thermal conductivity of a nanolayer still cannot be determined by experimental or theoretical means. However, 
the orderness and orientation of fluid molecules absorbed on a nanoparticle surface result in an intermediate value of thermal conductivity of nanolayer i.e., $\lambda_{\mathrm{f}}<\lambda_{\mathrm{lr}}<\lambda_{\mathrm{p}}$. Hence, the thermal conductivity nanolayer is given by $\lambda_{1 \mathrm{r}}=\omega \lambda_{\mathrm{f}}$, where $\omega>1$ is an empirical parameter which depends on the orderness of fluid molecules in the interface as well as the nature and surface chemistry of nanoparticle. In this study, $t=1 \mathrm{~nm}$ and $\omega=1.2$ were used.

The measured and predicted thermal conductivity of nanofluids and IoNanofluids were compared in our previous study [104] and it has been depicted here. It can be seen from Figure 8that while the recent model by Murshed et al. [36] (i.e., Eq.(4)) shows fairly good prediction of the effective thermal conductivity of $\left[\mathrm{C}_{4} \mathrm{mim}\right]\left[\mathrm{NTf}_{2}\right]$-based Ionanofluid at low concentration of multi-wall carbon nanotubes (MWCNT), classical Hamilton-Crosser model [103] severely over-predicts the results. It is noted that the weight concentrations of MWCNT were converted to corresponding volumetric concentrations for the predictions by both models. Due to almost identical thermal conductivity values of both base ionic liquids i.e., $\left[\mathrm{C}_{4} \mathrm{mim}\right]\left[\mathrm{NTf}_{2}\right]$ and $\left[\mathrm{C}_{2} \mathrm{mim}\right]\left[\mathrm{EtSO}_{4}\right]$, both models give similar predictions for $\left[\mathrm{C}_{2} \mathrm{mim}\right]$ $\left[\mathrm{EtSO}_{4}\right]$-based Ionanofluid [104]. However, at a high MWCNT concentration of 3 wt \% (equivalent to 19.3 volume \%) it is anticipated that the increase in thermal conductivity will not be as high as for the low concentration and any classical or recent model can easily overpredict the thermal conductivity at such a high concentration. This is mainly due to absence of dynamic mechanism for such high concentration.

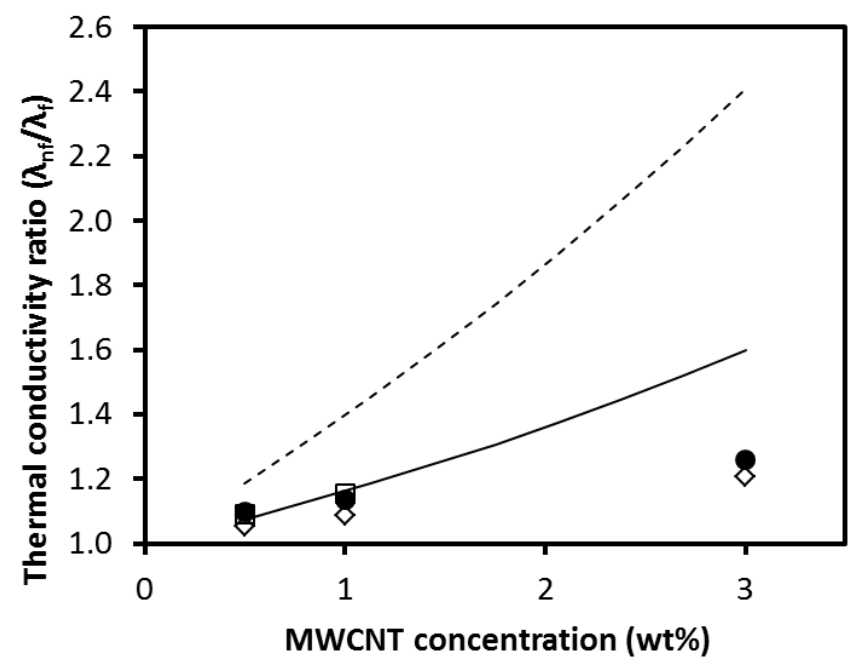

Figure 8. Comparison between predicted and measured thermal conductivity of nanofluids and loNanofluids as a

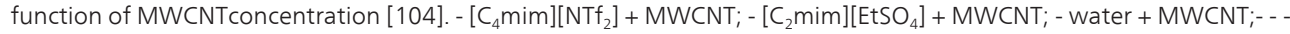
Eq. (3) for $\left[\mathrm{C}_{4}\right.$ mim $]\left[N T f_{2}\right]+$ MWCNT;Eq. (5) for $\left[\mathrm{C}_{4}\right.$ mim $]\left[N T f_{2}\right]+$ MWCNT.

Although by adjusting fitting parameters nanofluids' thermal conductivity models [36] can be used for IoNanofluids, it is important to understand the underlying mechanisms and to 
develop model for thermal conductivity and other thermo-physical properties of IoNanofluids by taking into account electrochemical factors and molecular level structuring and interactions of both the base ionic liquids and the dispersed nanoparticles.

\section{Conclusions and Looking Forward}

IoNanofluids are shown to be a very interesting class of nanofluids for many engineering applications, namely in heat transfer and storage. Although there are still a short number of publications with IoNanofluids, the number is definitely increasing, as a very recent paper with grapheme shows [105]. Regardless of the small current industrial production of ionic liquids, the base fluids, it is expected to increase in a short term, because the properties of ionic liquids are very attractive as green solvents and reactants. The evolution of their chemistry has been tremendous and therefore, the price of their production will decrease to levels that will make them competitive with current fluids used in industry.

The manufacture, handling and characterization of IoNanofluids is still in development, but it is thought that significant progress will be made in a near future, namely in the nanoparticles and emulsions characterization. Further fundamental and applied studies are needed.

One special topic of concern is the toxicity of IoNanofluids, a reflex not only of the toxicity of the base ionic liquids but also of the constituent nanomaterials. Depending on the ionic liquids used, the systems can be toxic and all the users must be aware of it. However those IoNanofluids based on hydrophilic ionic liquids are a safe choice. In addition, there is also a risk with the nanomaterials used, and there is a wide awareness of how important is to study their effect in vitro and in vivo systems. A wide range of physicochemical properties are relevant to toxicology, like particle size distribution, morphology, chemical composition, solubility and surface chemistry and reactivity. The specific interactions of the ionic liquids with the nanomaterials can alter the individual toxicity of them. Many studies are still necessary to reach all the necessary conclusions and compliance with existing legislation, namely in Europe.

The application of existing models to predict the behaviour of the IoNanofluids, namely the enhancement in the thermal conductivity, showed that it is fundamental to understand better the mechanism of heat transfer in these systems, namely the role played by the interface ionic liquid (cation and anion)-nanoparticle, whatever shape they have. This needs theoretical developments and molecular simulation studies that will give the insight for developing new heat transfer models.

\section{Acknowledgements}

This research was partially funded by FCT- Fundação para a Ciência e a Tecnologia, Portugal, through Centro de Ciências Moleculares e Materiais, PEst-OE/QUI/UI0536/2011 and PDCT/QUE-FTT/104614/2008. 


\section{Author details}

Carlos Nieto de Castro $^{1 *}$, Ana P. C. Ribeiro ${ }^{1}$, Salomé I.C. Vieira ${ }^{1}$, João M. P. França ${ }^{1}$, Maria J.V. Lourenço ${ }^{1}$, Fernando V. Santos ${ }^{1}$, Sohel M.S Murshed ${ }^{1}$, Peter Goodrich ${ }^{2}$ and Christopher Hardacre ${ }^{2}$

*Address all correspondence to: cacastro@fc.ul.pt

1 Departamento de Química e Bioquímica e Centro de Ciências Moleculares e Materiais Faculdade de Ciências, Universidade de Lisboa, Portugal

2 School of Chemistry and Chemical Engineering/QUILL, Queen's University, U. K.

\section{References}

[1] Holbrey, J. D., \& Rogers, R. D. (2008). Physicochemical Properties of Ionic Liquids: Melting Points and Phase Diagrams. In: Wasserscheid P, Welton T. (ed.) Ionic Liquids in Synthesis. Weinheim: VCH-Wiley, 57-72.

[2] Wasserscheid, P., \& Welton, T. (2008). editors. Ionic Liquids in Synthesis. 2nd Edcompletely revised and enlarged. Weinheim: $\mathrm{VCH}$-Wiley.

[3] Smiglak, M., Reichert, W. M., Holbrey, JD, Wilkes, J. S., Sun, L. Y., Thrasher, J. S., Kirichenko, K., Singh, S., Katritzky, A. R., \& Rogers, R. D. (2006). Combustible Ionic Liquids by Design: Is Laboratory Safety Another Ionic Liquid Myth? Chemical Communications, 24, 2554-2556, 10.1039/B602086K.

[4] Ngo, H. L., Le Compte, K., Hargens, L., \& Mc Ewen, A. B. (2000). Thermal Properties of Imidazolium Ionic Liquids. Thermochimica Acta, 357-358, 97-102.

[5] Baranyai, K. J., Deacon, G. B., Mac, Farlane. D. R., Pringle, J. M., \& Scott, J. L. (2004). Thermal Degradation of Ionic Liquids at Elevated Temperatures. Australian Journal of Chemistry, 57(2), 145-147.

[6] Gordon, C. M. (2001). New Developments in Catalysis Using Ionic Liquids. Applied Catalysis A: General, 222(1-2), 101-117.

[7] Rodrigues, F., Do Nascimento, G. M., \& Santos, P. S. (2007). Studies of Ionic Liquid Solutions by Soft X-ray Absorption Spectroscopy. Journal of Electron Spectroscopy and Related Phenomena, 155(1-3), 148-154.

[8] Crowhurst, L., Falcone, R., Lancaster, N. L., Liopis-Mestre, V., \& Welton, T. (2006). Using Kamlet-Taft Solvent Descriptors to Explain the Reactivity of Anionic Nucleophiles in Ionic Liquids. Journal of Organic chemistry, 71(10), 8847-8853.

[9] Ribeiro, A. P. C., Vieira, S. I. C., França, J. M. P., Queirós, C. S., Langa, E., Lourenço, M. J. V., Murshed, S. M. S., \& Nieto de Castro, CA. (2011). Thermal Properties of Ion- 
ic Liquids and IoNanofluids. In: Kokorin A. (ed.) Ionic Liquids: Theory, Properties, New Approaches. Rijeka: InTech, 36-60.

[10] Kamimura, H., Kubo, T., Minami, I., \& Mori, S. (2007). Effect and Mechanism of Additives for Ionic Liquids as New Lubricants. Tribology International, 40(4), 620-625.

[11] Mudring-V, A., Babai, A., Arenz, S., Giernoth, R., Binnemans, K., Driesen, K., \& Nockemann, P. (2006). Strong Luminescence of Rare Earth Compounds in Ionic Liquids: Luminescent Properties of Lanthanide(III) Iodides iIn the Ionic Liquid 1-dodecyl-3-methylimidazolium bis(trifluoromethanesulfonyl)imide. Journal of Alloys and Compounds, 418(1-2), 204-208.

[12] Fredlake, C. P., Muldoon, M. J., Aki, S. N. V. K., Welton, T., \& Brennecke, J. F. (2004). Solvent Strength of Ionic Liquid/CO2 Mixtures. Physical Chemistry Chemical Physics, 6(13), 3280-3285.

[13] Keskin, S., Kayrak-Talay, D., Akman, U., \& Hortaçsu, Ö. (2007). A Review of Ionic Liquids towards Supercritical Fluid Applications. The Journal of Supercritical Fluids, 43(1), 150-180.

[14] Earle, M. J., Katdare, S. P., \& Seddon, K. R. (2004). Paradigm Confirmed: The First Use of Ionic Liquids to Dramatically Influence the Outcome of Chemical Reactions. Organic Letters, 6(5), 707-710.

[15] Duan, Z., Gu, Y., \& Deng, Y. (2006). Green and Moisture-Stable Lewis Acidic Ionic Liquids (choline chloride $\mathrm{x} \mathrm{ZnCl}_{2}$ ) Catalyzed Protection of Carbonyls at Room Temperature under Solvent-free Conditions. Catalysis Communications, 7(9), 651-656.

[16] Doherty, S., Goodrich, P., Hardacre, C., Knight, J. G., Nguyen, M. T., Parvulescu, V. I., \& Paun, C. (2007). Recyclable Copper Catalysts Based on Imidazolium-Tagged Bis(oxazolines): A Marked Enhancement in Rate and Enantioselectivity for Diels-A1der Reactions in Ionic Liquid. Advanced Synthesis \& Catalysis, 349(6), 951-963.

[17] Hemeon, I., Barnett, N. W., Gathergood, N., Scammells, P. J., \& Singer, R. D. (2004). Manganese Dioxide Allylic and Benzylic Oxidation Reactions in Ionic Liquids. Australian Journal of Chemistry, 57(2), 125-128.

[18] Sowmiah, S., Srinivasadesikan, V., Tseng-C, M., \& Chu-H, Y. (2009). On the Chemical Stabilities of Ionic Liquids. Molecules, 14(9), 3780-3813.

[19] Carda-Broch, S., Berthod, A., \& Armstrong, D. W. (2003). Solvent Properties of the 1butyl-3-methylimidazolium Hexafluorophosphate Ionic Liquid. Analytical EBioanalytical Chemistry, 375(2), 191-199.

[20] Pârvulescu, V. I., \& Hardacre, C. (2007). Catalysis in Ionic Liquids. Chemical Reviews, 107(6), 2615-2665.

[21] Greaves, T. L., Weerawardena, A., Fong, C., Krodkiewska, I., \& Drummond, C. J. (2006). Protic Ionic Liquids: Solvents with Tunable Phase Behavior and Physicochemical Properties. Journal of Physical Chemistry B, 110(45), 22479-22487. 
[22] Seddon, K. R., Stark, A., \& Torres, M-J. (2000). Influence of Chloride, Water, and Organic Solvents on the Physical Properties of Ionic Liquids. Pure Applied Chemistry, 72(12), 275-287.

[23] Holbrey, J. D., \& Seddon, K. R. (1999). Ionic Liquids. Clean Products and Processes, 1(4), 223-236.

[24] Wasserscheid, P., \& Keim, W. (2000). Ionic Liquids-New "Solutions" for Transition Metal Catalysis. Angewandte Chemie International Edition, 39(21), 3772-3789.

[25] Welton, T. (2004). Ionic Liquids in Catalysis. Coordination Chemistry Reviews, 248(21-24), 459-477.

[26] Freemantle, M. (1998). Designer Solvents- Ionic Liquids May Boost Clean Technology Development. Chemical and Engineering News, 76(13), 32-37.

[27] Suarez, P. A. Z., Dullius, J. E. L., Einloft, S., de Souza, R. F., \& Dupont, J. (1997). TwoPhase Catalytic Hydrogenation of Olefins by Ru(II) and Co(II) Complexes Dissolved in 1-n-butyl-3-methylimidazolium Tetrafluoroborate Ionic Liquid. Inorganica Chimica Acta, 255(1), 207-209.

[28] Holbrey, J. D., Reichert, W. M., Swatloski, R. P., Broker, G. A., Pitner, W. R., Seddon, K. R., \& Rogers, R. D. (2002). Efficient, Halide Free Synthesis of New, Low Cost Ionic Liquids: 1,3-dialkylimidazolium Salts Containing methyl- and ethyl-sulfate Anions. Green Chemistry, 4(5), 407-413.

[29] Wasserscheid, P., van Hal, R., \& Bosmann, A. (2002). n-Butyl-3-methylimidazolium ([bmim]) octylsulfate-An Even 'Greener' Ionic Liquid. Green Chemistry, 4(4), 400-404.

[30] Wasserscheid, P., van Hal, R., Bösmann, A., Eßer, J., \& Jess, A. (2003). New Ionic Liquids Based on Alkylsulfate and Alkyl OligoetherSulfate Anions: Synthesis and Applications. In: Rogers R.D., Seddon K.R. (eds.) Ionic Liquids as Green Solvents. Washington D.C.: American Chemical Society, 57-69.

[31] Jessop, P. G., Mercer, S. M., \& Heldebrant, D. J. (2012). CO2-Triggered Switchable Solvents, Surfactants, and other Materials. Energy and Environmental Science, 5(6), 7240-7253.

[32] Choi, S. U. S. (1995). Enhancing Thermal Conductivity of Fluids with Nanoparticles. ASME FED, 231, 99-105.

[33] Lee, S., Choi, S. U. S., Li, S., \& Eastman, J. A. (1999). Measuring Thermal Conductivity of Fluids Containing Oxide Nanoparticles. Journal of Heat Transfer, 121(2), 280-289.

[34] Murshed, S. M. S., Leong, K. C., \& Yang, C. (2005). Enhanced Thermal Conductivity of $\mathrm{TiO}_{2}$-Water based Nanofluids. International Journal of Thermal Sciences, 44(4), 367-373.

[35] Murshed, S. M. S., Leong, K. C., \& Yang, C. (2006). Determination of the Effective Thermal Diffusivity of Nanofluids by the Double Hot-Wire Technique. Journal of Physics D: Applied Physics, 39(24), 5316-5322. 
[36] Murshed, S. M. S., Leong, K. C., \& Yang, C. (2008). Investigations of Thermal Conductivity and Viscosity of Nanofluids. International Journal of Thermal Sciences, 47(5), 560-568.

[37] Murshed, S. M. S., Leong, K. C., \& Yang, C. (2008). Thermophysical and Electrokinetic Properties of Nanofluids- A Critical Review. Applied Thermal Engineering, 28(17-18), 109-125.

[38] Yu, W., France, D. M., Routbort, J. L., \& Choi, S. U. S. (2008). Review and Comparison of Nanofluid Thermal Conductivity and Heat Transfer Enhancements. Heat Transfer Engineering, 29(5), 432-460.

[39] You, S. M., Kim, J. H., \& Kim, K. M. (2003). Effect of Nanoparticles on Critical Heat Flux of Water in Pool Boiling of Heat Transfer. Applied Physics Letters, 83(16), 3374-3376.

[40] Wen, D., \& Ding, Y. (2004). Experimental Investigation into Convective Heat Transfer of Nanofluids at the Entrance Region under Laminar Flow Conditions. International Journal of Heat and Mass Transfer, 47(24), 5181-5188.

[41] Wen, D., \& Ding, Y. (2005). Experimental Investigation into the Pool Boiling Heat Transfer of Aqueous based Alumina Nanofluids. Journal of Nanoparticle Research, $7(2-3), 265-274$.

[42] Bang, I. C., \& Chang, S. H. (2005). Boiling Heat Transfer Performance and Phenomena of Al2O3-Water Nano-Fluids from a Plain Surface in a Pool. International Journal of Heat and Mass Transfer, 48(12), 2407-2419.

[43] Heris, S. Z., Etemad, S. G., \& Esfahany, M. S. (2006). Experimental Investigation of Oxide Nanofluids under Laminar Flow Convective Heat Transfer. International Communications of Heat Mass Transfer, 33(4), 529-535.

[44] Murshed, S. M. S., Leong, K. C., Yang, C., \& Nguyen, N. T. (2008). Convective Heat Transfer Characteristics of Aqueous $\mathrm{TiO}_{2}$ Nanofluids under Laminar Flow Conditions. International Journal of Nanoscience, 7(6), 325-331.

[45] Murshed, S. M. S., Milanova, D., \& Kumar, R. (2009). An Experimental Study of Surface Tension-Dependent Pool Boiling Characteristics of Carbon Nanotubes-Nanofluids. In: Proceedings of the 7th ASME International Conferences on Nanochannels, Microchannels and Minichannels (ICNMM'09), Pohang, South Korea June., 22-24.

[46] Choi, S. U. S., Zhang, Z., Yu, W., Lockwood, F., \& Grulke, E. (2001). Anomalous Thermal Conductivity Enhancement in Nanotube Suspensions. Applied Physics Letters, 79(14), 2252-2254.

[47] Ding, Y., Alias, H., Wen, D., \& Williams, R. A. (2006). Heat Transfer of Aqueous Suspensions of Carbon Nanotubes (CNT Nanofluids). International Journal of Heat and Mass Transfer, 49(1-2), 240-250. 
[48] Ribeiro, A.P.C, Lourenço, M.J.V, Nieto de Castro, CA, \& Hardacre, C. (2008). Thermal Conductivity of "Bucky Gels". In: Proceedings of Conference on Molten Salts and Ionic Liquids (EUCHEM2008), Copenhagen, Denmark August, 24-29.

[49] Ribeiro, A. P. C., Lourenço, M. J. V., \& Nieto de Castro, C. A. (2009). Thermal Conductivity of IoNanofluids. In: Proceedings of 17th Symposium on Thermophysical Properties, Boulder, USA June., 21-26.

[50] Nieto de Castro, CA, Lourenço, M. J. V., Ribeiro, A. P. C., Langa, E., Vieira, S. I. C., Goodrich, P., \& Hardacre, C. (2010). Thermal Properties of Ionic Liquids and IoNanofluids of Imidazolium and Pyrrolidinium Liquids. Journal of Chemical Engineering Data, 55(2), 653-661.

[51] Fukushima, T., Kosaka, A., Ishimura, Y., Yamamoto, T., Takigawa, T., Ishii, N., \& Aida, T. (2003). Molecular Ordering of Organic Molten Salts Triggered by Single-Walled Carbon Nanotubes. Science, 300(5628), 2072-2074.

[52] Fukushima, T., \& Aida, T. (2007). Ionic Liquids for Soft Functional Materials with Carbon Nanotubes. Chemistry-A European Journal, 13(18), 5048-5058.

[53] Murshed, S. M. S., \& Nieto de Castro, C.A. (2012). Nanofluids as Advanced Coolants. In: Mohammad A., Inamuddin (eds.) Green Solvents I: Properties and Applications in Chemistry. Dordrecht: Springer, 397-415.

[54] Nieto de Castro, CA, Murshed, S. M. S., Lourenço, M. J. V., Santos, F. J. V., Lopes, M. L. M., \& França, J. M. P. (2012). IoNanofluids- New Heat Transfer Fluids for Green Process Development. In: Mohammad A., Inamuddin (eds.) Green Solvents I: Properties and Applications in Chemistry. Dordrecht: Springer, 233-249.

[55] Murshed, S. M. S., \& Nieto de Castro, C. A. (2011). Forced Convective Heat Transfer of Nanofluids in Minichannels. In: Ahsan A. (ed.) Two Phase Flow, Phase Change and Numerical Modeling. Rijeka: InTech.

[56] Keblinski, P., Prasher, R., \& Eapen, J. (2008). Thermal Conductance of Nanofluids: Is the Controversy Over? Journal of Nanoparticle Research, 10(7), 1089-1097.

[57] Patil, V. S., Krishna, S. R., Hadalwar, R. R., Gaikwad, A. B., Sathaye, S. D., \& Patil, K. R. (2011). One-Step In Situ Synthesis of Nhx-Adsorbed Rhodium Nanocrystals in Liquid-Liquid Interfaces for Possible Electrocatalytic Applications. Journal of Colloid and Interface Science, 358(1), 238-244.

[58] Patil, V., Hadalwar, R., Sathaye, S., Joshi, M., Salavera, D., \& Coronas, A. (2012). One Pot Synthesis of Aqueous Gold Nanoparticles Dispersion without External Reducing or/and Dispersing/Capping Agent. Chemical Communications (submitted).

[59] Nieto de Castro, C. A. (2010). Thermophysical Properties of Ionic Liquids: Do We Know How to Measure them Accurately? Journal of Molecular Liquids, 156(1), 10-17.

[60] França, J. M. P., Vieira, S. I. C., Murshed, S. M. S., Lourenço, M. J. V., \& Nieto de Castro, C. A. (2012). Thermal Conductivity of [C2mim][dca], [C4mim][dca] and 
[C4mpyr][dca] and their IoNanofluids with Nanosystems. Fluid Phase Equilibria (to be submitted).

[61] Vieira, S. I. C., Lourenço, M. J., \& Nieto de Castro, C. A. (2012). Paints with IoNanofluids as Pigments for Improvement of Heat Transfer on Architectural and Heat Exchangers Surfaces. In: Proceedings of 18th Symposium on Thermophysical Properties, Boulder, USA June., 24-29.

[62] Queirós, C. S., Vieira, S. I. C., Lourenço, M. J. V., \& Nieto de, Castro. C. A. (2012). Study of Fruit Waste Reuse as New Thermal Absorbing Materials. In: Proceedings of 18th Symposium on Thermophysical Properties, Boulder, USA June., 24-29.

[63] Queirós, C. S., Vieira, S. I., Lourenço, M. J. V., \& Nieto de Castro, C. A. (2012). Natural Nano Resources to Enrich Scientific and Economical Global Needs. In: Proceedings of International Workshop on Ionic Liquids- Seeds for New Engineering Applications (WILS2012) Lisbon, Portugal February., 2-3.

[64] Nunes, V. M. B., Lourenço, M. J. V., Santos, F. J. V., Matos, M. L. M., \& Nieto de, Castro. C. A. (2010). Accurate Measurements of Physico-Chemical Properties on Ionic Liquids and Molten Salts. In: Gaune-Escard M, Seddon K.E. (eds.) Ionic Liquids and Molten Salts: Never the Twain. London: John Wiley, 229-263.

[65] Widegren, J. A., Laesecke, A., \& Magee, J. W. (2005). The Effect of Dissolved Water on the Viscosities of Hydrophobic Room-Temperature Ionic Liquids. Chemical Communications; 10.1039/B417348A, 12, 1610-1612.

[66] Widegren, J. A., \& Magee, J. W. (2007). Density, Viscosity, Speed of Sound, and Electrolytic Conductivity for the Ionic Liquid 1-Hexyl-3-Methylimidazolium Bis(trifluoromethylsulfonyl)imide and its Mixtures with Water. Journal of Chemical Engineering Data, 52(6), 2331-2338.

[67] Van Valkenburg, ME, Vaughn, R. L., Williams, M., \& Wilkes, J. S. (2005). Thermochemistry of Ionic Liquid Heat-Transfer Fluids. ThermochimicaActa, 425(1-2), 181-188.

[68] Rebelo, L. P. N., Najdanovic-Visak, V., Visak, Z. P., Nunes, da., Ponte, M., Szydlowski, J., Cerdeirina, CA, Troncoso, J., Romani, L., Esperanca, J. M. S. S., Guedes, H. J. R., \& de Sousa, H. C. (2004). A Detailed Thermodynamic Analysis of $\left[\mathrm{C}_{4} \mathrm{mim}\right]\left[\mathrm{BF}_{4}\right]+$ Water as a Case Study to Model Ionic Liquid Aqueous Solutions. Green Chemistry, 6(8), 369-381.

[69] Kim, K. S., Shin, B. K., \& Ziegler, F. (2004). Refractive Index and Heat Capacity of 1Butyl-3-Methylimidazolium Bromide and 1-Butyl-3-Methylimidazolium Tetrafluoroborate, and Vapor Pressure of Binary Systems for 1-Butyl-3-Methylimidazolium Bromide + Trifluoroethanol and 1-Butyl-3-Methylimidazolium Tetrafluoroborate + Trifluoroethanol. Fluid Phase Equilibria, 218(2), 215-220.

[70] Fredlake, C. P., Crosthwaite, J. M., Hert, D. G., Aki, S. N. V. K., \& Brennecke, J. F. (2004). Thermophysical Properties of Imidazolium-based Ionic Liquids. Journal of Chemical Engineering Data, 49(4), 954-964. 
[71] Waliszewski, D., Stepniak, I., Piekarski, H., \& Lewandowski, A. (2005). Heat Capacities of Ionic Liquids and their Heats of Solution in Molecular Liquids. ThermochimicaActa, 433(1-2), 149-152.

[72] Garcia-Miaja, G., Troncoso, J., \& Romani, L. (2008). Excess Properties for Binary Systems Ionic Liquid Plus Ethanol: Experimental Results and Theoretical Description using the ERAS Model. Fluid Phase Equilibria, 274(1-2), 59-67.

[73] Garcia-Miaja, G., Troncoso, J., \& Romani, L. (2009). Excess Molar Properties for Binary Systems of Alkylimidazolium-Based Ionic Liquids Plus Nitromethane. Experimental Results and ERAS-Model Calculations. Journal of Chemical Thermodynamics, 41(3), 334-341.

[74] França, J. M. P., Nieto de, Castro. . C. A., Nunes, V. M. B., \& Lopes, M. L. M. (2009). The Influence of Thermophysical Properties of Ionic Liquids in Chemical Process Design. Journal of Chemical Engineering Data, 54(9), 2569-2575.

[75] Ionic Liquids Database- (IL Thermo), NIST Standard Reference Database \#147. (2006). US Secretary of Commerce., http://ilthermo.boulder.nist.gov/ILThermo/mainmenu.uix.

[76] Pacheco, J. E., Showalter, S. K., \& Kolb, W. J. (2001). Development of a Molten-Salt Thermocline Thermal Storage System for Parabolic Trough Plants. In: Proceedings of the Solar Forum Solar Energy: The Power to Choose, Washington D.C., USA April 2001., 21-25.

[77] Nunes, V. M. B., Lourenço, M. J. V., Santos, F. J. V., \& Nieto de Castro, CA. (2003). The Importance of the Accurate Data on Viscosity and Thermal Conductivity in Molten Salts Applications. Journal of Chemical Engineering Data, 48(3), 446-450.

[78] Gardas, R. L., Freire, M. G., Carvalho, P. J., Marrucho, I. M., Fonseca, I. M. A., Ferreira, A. G., \& Coutinho, J. A. P. (2007). High-Pressure Densities and Derived Thermodynamic Properties of Imidazolium-based Ionic Liquids. Journal of Chemical Engineering Data, 52(1), 1880-1888.

[79] Holbrey, J. D., Reichert, W. M., Reddy, R. G., \& Rogers, R. D. (2003). Heat Capacities of Ionic Liquids and Their Applications as Thermal Fluids. In: Rogers R.D., Seddon K.R. (eds.) Ionic Liquids as Green Solvents. Washington D.C.: American Chemical Society, 121-133.

[80] Pereiro, A. B., Legido, J. L., \& Rodriguez, A. (2007). Physical Properties of Ionic Liquids based on 1-alkyl-3-Methylimidazolium Cation and Hexafluorophosphate as Anion and Temperature Dependence. The Journal of Chemical Thermodynamics, 39(8), 1168-1175.

[81] Tomida, D., Kenmochi, S., Tsukada, T., Qiao, K., \& Yokoyama, C. (2007). Thermal Conductivities of $\left[\mathrm{C}_{4} \mathrm{mim}\right]\left[\mathrm{PF}_{6}\right],\left[\mathrm{C}_{6} \mathrm{mim}\right]\left[\mathrm{PF}_{6}\right]$, and $\left[\mathrm{C}_{8} \mathrm{mim}\right]\left[\mathrm{PF}_{6}\right]$ from 294 to $335 \mathrm{~K}$ at Pressures up to $20 \mathrm{MPa}$. International Journal of Thermophysics, 28(4), 1147-1160. 
[82] Zhang, S., Li, X., Chen, H., Wang, J., Zhang, J., \& Zhang, M. (2004). Determination of Physical Properties for the Binary System of 1-Ethyl-3-methylimidazolium Tetrafluoroborate + H2O. Journal of Chemical Engineering Data, 49(4), 760-764.

[83] Huddleston, J. G., Visser, A. E., Reichert, W. M., Willauer, H. D., Broker, G. A., \& Rogers, R. D. (2001). Characterization and Comparison of Hydrophilic and Hydrophobic Room Temperature Ionic Liquids Incorporating the Imidazolium Cation. Green Chemistry, 3(4), 156-164.

[84] Smith, R. (2005). Chemical Process: Design and Integration. UK: John Wiley E Sons.

[85] Massonne, K. (2012). Ionic liquids at BASF SE: Introduction and Technical Applications. In: Proceedings of International Workshop on Ionic Liquids- Seeds for New Engineering Applications (WILS2012), Lisbon, Portugal February., 2-3.

[86] França, J. M. P., Nieto de Castro, C. A., Lopes, M. L. M., \& Murshed, S. M. S. (2012). Evidence of Economic Impact of Quality Measurements. In: Proceedings of International Workshop on Ionic Liquids- Seeds for New Engineering Applications (WILS2012), Lisbon, Portugal February., 2-3.

[87] Petkovic, M., Seddon, K. R., Rebelo, L. P. N., \& Pereira, C. S. (2011). Ionic liquids: a pathway to environmental acceptability. Chemical Society Reviews, 40-1383.

[88] Vibouda, S., Papaiconomoub, N., Cortesia, A., Chatelb, G., Drayeb, M., \& Fontvieille, D. (2012). Correlating the structure and composition of ionic liquids with their toxicity on Vibrio fischeri: A systematic study. Journal of Hazardous Materials, 215-216(1), 40-48.

[89] REACH-Registration. Evaluation, Authorisation and Restriction of CHemicals. http:// ec.europa.eu/enterprise/sectors/chemicals/reach/index_en.htm.

[90] Hartung, T., \& Rovida, C. (2009). Nature, 460-1080.

[91] Ionic Liquids from BASF-Solutions for Your Success. http://ionmet.eu/fileadmin/ ionmet/training/20090324_Munich/9_Vagt_REACH.pdf.

[92] Torrecilla, J. S., Palomar, J., Lemus, J., \& Rodriguez, F. (2010). A quantum-chemicalbased guide to analyze/quantify the cytotoxicity of ionic liquids. Green Chemistry, 12-123.

[93] Palomar, J., Torrecilla, J. S., Lemus, J., Ferro, V. R., \& Rodriguez, F. (2010). A COSMO-RS based guide to analyze/quantify the polarity of ionic liquids and their mixtures with organic cosolvents. Physical Chemistry Chemical Physics, 12, 2991-2000.

[94] Matzke, M., Stolte, S., Böschen, A., \& Filser, J. (2008). Mixture effects and predictability of combination effects of imidazolium based ionic liquids as well as imidazolium based ionic liquids and cadmium on terrestrial plants (Triticumaestivum) and limnic green algae (Scenedesmusvacuolatus). Green Chemistry, 10-784. 
[95] Sayes, C. M., \& Warheit, D. B. (2009). Characterization of nanomaterials for toxicity assessment. Wiley Interdisciplinary Reviews Nanomedicine and Nanobiotechnology, 1(6), 660-670.

[96] Regulatory Aspects of Nanomaterials. Summary of legislation in relation to health, 2008 safety and environment aspects of nanomaterials, regulatory research needs and related measures. COM(2008) 366 final; CEC, Brussels, 1-45.

[97] Riediker, M., \& Katalagarianakis, G. (2012). Compendium of Projects in the European NanoSafety Cluster.

[98] Dawson, K. A., Anguissola, S., \& Lynch, I. (2012). The need for in situ characterisation in nanosafety assessment: funded transnational access via the QNano research infrastructure. Nanotoxicology, 10.3109/17435390.2012.658096.

[99] Kunz, W., Maurer, E., Klein, R., Touraud, D., Rengstl, D., Harrar, A., Dengler, S., \& Zech, O. (2011). Low Toxic Ionic Liquids, Liquid Catanionics, and Ionic Liquid Microemulsions. Journal of Dispersion Science and Technology, 32-1694.

[100] Carrera, G. V. S. M., Frade, R. F. M., Aires-de-Sousa, J., Afonso, C. A. M., \& Branco, L. C. (2010). Synthesis and properties of new functionalized guanidinium based ionic liquids as non-toxic versatile organic materials. Tetrahedron, 66-8785.

[101] http://echa.europa.eu/.

[102] Maxwell, J. C. (1891). A Treatise on Electricity and Magnetism. Oxford: Clarendon Press.

[103] Hamilton, R. L., \& Crosser, O. K. (1962). Thermal Conductivity of Heterogeneous Two Component Systems. Industrial E Engineering Chemistry Fundamentals, 1(3), 187-191.

[104] Nieto de Castro, C. A., Murshed, S. M. S., Lourenço, M. J. V., Santos, F. J. V., Lopes, M. L. M., \& França, J. M. P. (2012). Enhanced thermal conductivity and specific heat capacity of carbon nanotubes IoNanofluids. International Journal of Thermal Sciences (2012), 10.1016/j.ijthermalsci.03.010.

[105] Wang, F., Han, L., Zhang, Z., Fang, X., Shi, J., \& Ma, W. (2012). Surfactant-free ionic liquid-based nanofluids with remarkable thermal conductivity enhancement at very low loading of grapheme. Nanoscale Research Letters 10.1186/1556-276X-7-314On line 19 June 2012., 7(314) 
